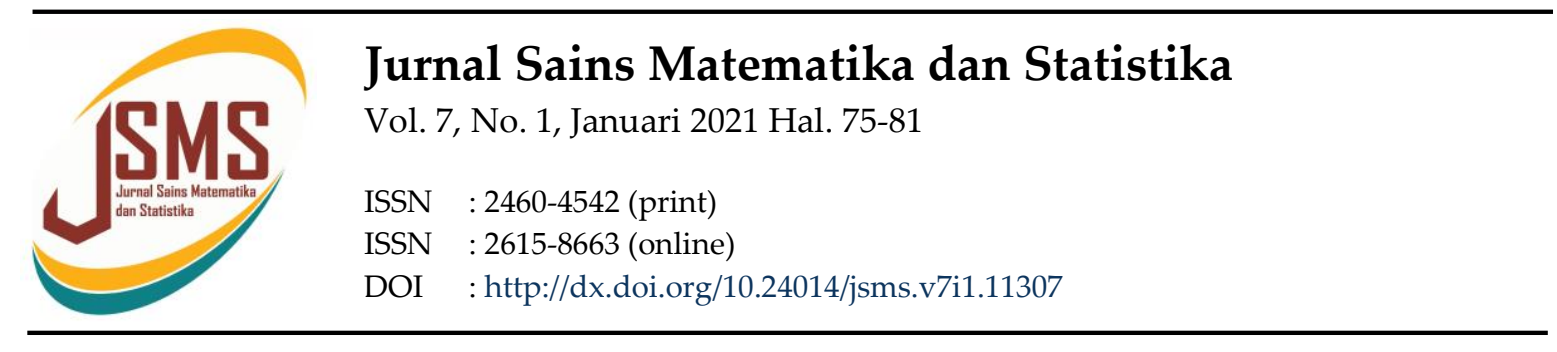

\title{
Penyelesaian Pemrograman Linear dengan Metoda Modifikasi Proyeksi Gradien
}

\author{
Endang Lily ${ }^{1}$, Lely Deswita ${ }^{2}$, Horison ${ }^{3}$ \\ 1,2,3 Jurusan Matematika, Universitas Riau \\ Jl. HR Soebrantas KM 12,5, Kampus Bina WidyaSimpangBaru, Pekanbaru, 28293 \\ Email: endang.lily60@gmail.com, deswit@yahoo.com, sonmsi@yahoo.co.id, \\ ${ }^{*}$ Korespondensipenulis :endang.lily60@gmail.com
}

\begin{abstract}
Abstrak
Sembarang titik dalam daerah fisibel pada sebuah pemrograman linear dengan bantuan matriks proyeksi dapat bergerak lurus memotong tegak lurus vektor gradien fungsi obyektif. Kemudian titik fisibel pada vektor gradien diteruskan pergerakannya oleh garis fungsi obyektif sepanjang kelipatan panjang pergerakan sebelumnya sehingga memotong garis kendala. Selanjutnya titik potong pada kendala tersebut diuji optimalitasnya dengan menggunakan syarat Kuhn-Tuker.
\end{abstract}

Kata Kunci: Pemrograman linear, matriks proyeksi,solusi optimum dan syarat KuhnTucker

\begin{abstract}
Any point in the feasible region in a linear programming with the help of a projection matrix can move perpendicularly across the gradient vector of the objective function. Then the feasible point on the gradient vector is continued in motion by the objective function line along the multiple of the length of the previous movement so that it intersects the constraint line. Furthermore, the point intersection of the constraint is tested for optimality using the Kuhn-Tucker conditions.
\end{abstract}

Keywords: Linear programming, projection matrix, optimum solution and Kuhn-Tucker condition

\section{Pendahuluan}

Pemrograman Linear adalah salah satu rumus masalah optimisasi yang banyak membantu untuk mendapatkan keputusan terbaik dalam kegiatan memproduksi barang, kegiatan ekonomi, sosial, perencanaan pembangunan rumah dan lain-lain. [1] dan [3]. Metoda Simpleks adalah sebuah metoda yang sudah lama dikenal dapat memberikan penyelesaian pemrograman linear dan metoda ini pertama kali dikembangkan oleh Dantzig pada tahun 1947. Adapun proses untuk mencapai solusi optimum pada pemrograman linear ini dapat direpresentasikan sebagai pergerakan sebuah titik fisibel 
ekstrim melalui garis kendala menuju titik fisibel ekstrim lainnya hingga didapatkan solusi optimum. Selanjutnya berkaitan dengan proses menentukan solusi optimum pada pemrograman linear tersebut dapat ditinjau proses menentukan solusi optimum pada pemrograman nonlinear. Dalam pemrograman nonlinear didapatkan titik fisibel sembarang dalam daerah fisibel dengan bantuan matriks proyeksi dapat bergerak lurus memotong tegak lurus gradien vektor. Kemudian titik tersebut diteruskan pergerakannya sepanjang kelipatan dengan panjang sebelumnya sehingga memotong garis kendala dan titik fisibel tidak keluar dari daerah fisibelSelanjutnya titik potong dengan garis kendala dapat diuji optimalitasnya dengan menguji nilai vektor gradien adalah vektor nol.Salah satu metoda ini dikenal dengan metoda proyeksi gradien[2]. Berkaitan dengan metoda proyeksi gradien pada pemrograman nonlinear tersebut dapat ditinjau hasil penelitian S,Tantawi (2019) dalam [4] bahwa sembarang titik dalam daerah fisibel sebuah pemrograman linear dengan bantuan matriks proyeksi dapat bergerak lurus memotong tegak lurus garis fungsi obyektif. Selanjutnya titik tersebut dibawa oleh garis fungsi obyektif sepanjang kelipatan dengan panjang sebelumnya sehingga memotong garis kendala yang terdekat.Selanjutnya titik potong tersebut dapat diuji optimalitasnya dengan menggunakan syarat Kuhn-Tucker. Dari hasil tinjauan di dalam menggerakkan titik fisibel menuju solusi optimum pada pemrograman nonlinear dan linear terdapat persamaan masing-masing memerlukan bantuan matriks proyeksi. Sedangkan perbedaannya adalah bahwa pada pemrograman nonlinear didalam menentukan kelipatan panjang berikutnya sehingga memotong garis kendala dan dijamin solusi tidak keluar daerah fisibel maka dengan bantuan teorema turunan fungsi ditentukan nilai minimum fungsi obyektif. Sedangkan pada pemrograman linear dalam menentukan kelipatan panjang berikutnya digunakan nilai minimum dari setiap selisih ruas kanan dan kiri kendala pada pemrograman linear. Berdasarkan perbedaan cara menentukan kelipatan panjang berikutnya sehingga solusi tidak keluar dari daerah fisibel maka pada penyelesaian pemrograman linear ini untuk selanjutnya disebut metoda modifikasi proyeksi gradien.

\section{MetodePenelitian}

Penelitian ini adalah studi literatur, yaitu hal-hal yang berkaitan dengan pemunculan masalah bersumber pada jurnal dan buku teks.Begitu juga segala pemecahan masalah merujuk pada jurnal dan bukuteks.

\subsection{LandasanTeori}

Dalam [3] diuraikan bentuk umum pemrograman linear:

$$
\begin{aligned}
\text { Maksimum } F(X)=P X & \\
\text { kendala } A X & \leq b \\
X & \geq 0
\end{aligned}
$$

$$
\begin{aligned}
& \text { dengan } X=\left(x_{1}, x_{2}, \ldots, x_{n}\right)^{T}, P=\left(c_{1}, c_{2}, \ldots, c_{n}\right), 0=(0,0, \ldots, 0)^{T}, b=\left(b_{1}, b_{2}, \ldots, b_{n}\right)^{T} \text { dan } \\
& A=\left(a_{i j}\right) \text { dengan } i=1,2, \ldots, m, j=1,2, \ldots, n . \\
& \text { dan } U^{T}=\left(u_{1}, u_{2}, \ldots, u_{m}\right)
\end{aligned}
$$


Dari Persamaan (1) diperoleh syarat Kuhn-Tucker sebagai berikut, [2]

$$
X\left(P-U^{T} A\right)=0 .
$$

Dengan menetapkan $X \neq 0$ maka diperoleh

$$
U^{T}=P A^{-1}
$$

Dari Persamaan (2) diperoleh $U$ adalah variabel masalah dual pemrograman linear pada Persamaan(1). Dengan demikian berdasarkan [1] dapat ditemukan $U \neq \mathbf{0}$ sedemikian hingga diperoleh,

$$
F\left(X^{\circ}\right)=P X^{\circ}=b^{T} U
$$

dengan $X^{\circ}$ adalah solusi optimal masalah pada Persamaan (1).

Berdasarkan Persamaan (3) bahwa setiap solusi masalah pada Persamaan (1) dapat diuji optimalitasnya. Dengan demikian dapatlah dibuat pergerakan sembarang titik fisibel menuju solusi optimal. Selanjutnya yang menjadi masalah langkah apa yang harus dibuat agar pergerakan sembarang titik dalam daerah fisibel pada pemrograman linear dapat mencapai solusi optimal.

\subsection{Metode/Metodologi Penelitian}

Definisi1 [2] MatriksHdengan ordo nxn adalah matriks proyeksi bila

$$
\boldsymbol{H}=\boldsymbol{H}^{T} \text { dan } \boldsymbol{H} \boldsymbol{H}=\boldsymbol{H}
$$

Lemma 1 [2] Matriks $\boldsymbol{H}$ dengan ordo $\mathbf{n} \mathbf{x} \mathbf{n}$ adalah matriks proyeksi jika dan hanya jika $\boldsymbol{I}-\boldsymbol{H}$ adalah matriks proyeksi

Matriks proyeksi ini digunakan untuk mendapatkan arah lurus pergerakan titik fisibel hingga memotong tegak lurus dengan gradien vektor fungsi obyektif dan tidak lain vektor gradien tersebut adalah garis fungsi obyektif. Kemudian pergerakan titik fisibel tersebut dilanjutkan dengan panjang kelipatan panjang pergerakan sebelumnya sehingga memotong garis kendala dan tidak keluar daerah fisibel.

Berkaitan dengan keadaan pergerakan titik fisibel tersebut maka dapat dirumuskan setiap solusi fisibel sebagai berikut:

$$
X^{k}=X^{k-1}+\alpha_{k-1} d^{k-1}, k=1,2
$$


dengan

$$
d^{k-1}=H_{k-1} P^{T}
$$

adalah vektor arah menuju garis kendala dengan $\boldsymbol{H}_{\boldsymbol{k}-\mathbf{1}}$ adalah matriks proyeksi yang menggerakan titik fisibel memotong tegak lurus gradien vektor yang dirumuskan

$$
\boldsymbol{H}_{k-1}= \begin{cases}\boldsymbol{I} \text { bila } & k=1 \\ \boldsymbol{H}_{k-1}^{q} \text { bila } & k>1\end{cases}
$$

dengan $\boldsymbol{I}$ adalah matriks identitas, $\boldsymbol{P}^{T}$ adalah gradien vektor fungsi obyektif dan $\alpha_{k-1}$ adalah kelipatan panjang sebelumnya hingga memotong garis kendala dan solusi tidak keluar dari daerah fisibel dirumuskan.

$$
\alpha_{k-1}=\min \left\{g_{i}, g_{i}=\frac{b-a X_{k}}{a d^{T}} \text { dan } g_{i}>0\right\} i=1,2 \ldots, m
$$

Persamaan (5) merupakan adalah selisih ruas kanan dan kiri setiap kendala pada pemrograman linear untuk a adalah koefusien fungsi kendala. Dengan demikian dari Persamaan (4) dapat dinyatakan sembarang titik, $\boldsymbol{X}^{\boldsymbol{k}-1}$ dengan bantuan matriks proyeksi bergerak memotong tegak lurus gradient vektor dalam hal ini adalah garis fungsi obyektif. Kemudian pergerakan titik tersebut dilanjutkan sepanjang kelipatan panjang sebelumnya hingga diperoleh titik potong dengan garis kendala, $X^{k}=X^{k-1}+\alpha_{k-1} d^{k-1}, k=1,2$. Selanjutnya optimalitasnya diuji dengan menggunakan Persamaan (3). Jika tidak dipenuhi maka solusi optimum belum dicapai. Oleh karena itu harus diulang lagi menentukan mariks proyeksi yang baru hingga diperoleh solusi optimum yang baru.Selanjutnya langkah mencari solusi optimum pada pemrograman linear ini disebut metoda modifikasi proyeksi gradien.

\section{Hasil dan Pembahasan}

Akhir dari pembahasan dalam penelitian ini diperoleh sebuah hasil alternative metoda penyelesaian pemrograman linear yang disebut metoda modifikasi proyeksi gradient.Hasil penelitian ini terbentuk dalam sebuah algoritma sebaga berikut:

\subsection{Algoritma Penyelesaian Pemrograman Linear}

Berikutnya dapat diuraikan langkah-langkah menyelesaikan pemrograman linear dengan metoda modifikasi proyeksi gradien.

Langkah 0 : Ambil $\mathrm{k}=1, \boldsymbol{H}_{\mathbf{0}}=\boldsymbol{I}$, misalkan $\boldsymbol{X}^{\mathbf{0}}$ adalah basis awal dengan menggunakan Persamaan (7) diperoleh $\propto_{0}$.

Langkah 1 : Dengan menggunakan Persamaan (4) diperoleh $\boldsymbol{X}^{\boldsymbol{k}}$. 
Langkah 2 : Dengan menggunakan Persamaan (2) dapat ditemukan $\boldsymbol{U} \neq 0$ sehingga $\boldsymbol{W}(\boldsymbol{U})=\boldsymbol{b} \boldsymbol{U}^{\boldsymbol{T}}=\boldsymbol{F}\left(\boldsymbol{X}^{\boldsymbol{o}}\right)$, artinya nilai optimum masalah primal sama dengan nilai Optimal masalah dual. Lainnya,kembali ke langkah 3.

Langkah 3: Susun $k=$ k+1dengan menggunakan Persamaan (6), (5) dan (7) masingmasing diperoleh

$\boldsymbol{H}_{\boldsymbol{k}-1}, \boldsymbol{d}^{\boldsymbol{k}-1}$ dan $\propto_{k-1}$ dan lanjut ke langkah 1.

\subsection{Penyelesaian Pemrograman Linear}

$$
\begin{array}{r}
\text { Maksimum Z= } 3 x_{1}+2 x_{2}+5 x_{3} \\
\text { Kendala, } 1 x_{1}+2 x_{2}+x_{3} \leq 4,3 \\
3 x_{1}+0 x_{2}+2 x_{3} \leq 4,6 \\
1 x_{1}+4 x_{2}+0 x_{3} \leq 4,2 \\
x_{1}, x_{2}, x_{3} \geq 0
\end{array}
$$

Berdasarkan Syarat Kuhn-Tucker pada Persamaan (1) diperoleh

$$
\begin{gathered}
A^{T} U=P^{T} \rightarrow\left(\begin{array}{lll}
1 & 3 & 1 \\
2 & 0 & 4 \\
1 & 2 & 0
\end{array}\right)\left(\begin{array}{l}
U_{1} \\
U_{2} \\
U_{3}
\end{array}\right)=\left(\begin{array}{l}
3 \\
2 \\
5
\end{array}\right) \text {,sehingga } \\
\boldsymbol{U}=\left(A^{T}\right)^{-1} P^{T} \rightarrow\left(\begin{array}{l}
U_{1} \\
U_{2} \\
U_{3}
\end{array}\right)=\left(\begin{array}{ccc}
-1, & 0,25 & 1,5 \\
0,5 & -0,125 & -0,25 \\
0,5 & 0,125 & -0,75
\end{array}\right)\left(\begin{array}{l}
3 \\
2 \\
5
\end{array}\right)=\left(\begin{array}{c}
5 \\
0 \\
-2
\end{array}\right)
\end{gathered}
$$

Jadi nilai optimal solusi masalah dual adalah

$\boldsymbol{W}(\boldsymbol{U})=\boldsymbol{b}^{\boldsymbol{T}} \boldsymbol{U}=\left(\begin{array}{lll}4,3 & 4,6 & 4,2\end{array}\right)\left(\begin{array}{c}5 \\ 0 \\ -2\end{array}\right)=\mathbf{1 3 , 1}$

$$
\begin{aligned}
\text { Langkah } 0 \quad: & \mathrm{k}=1, \boldsymbol{H}_{\mathbf{0}}=\left(\begin{array}{lll}
\mathbf{1} & \mathbf{0} & \mathbf{0} \\
\mathbf{0} & \mathbf{1} & \mathbf{0} \\
\mathbf{0} & \mathbf{0} & \mathbf{1}
\end{array}\right), \boldsymbol{P}^{T}=\left(\begin{array}{l}
\mathbf{3} \\
\mathbf{2} \\
\mathbf{5}
\end{array}\right) \text {, titik fisibel } \boldsymbol{X}^{\mathbf{0}}=\left(\begin{array}{c}
0,5 \\
0,5 \\
0,5
\end{array}\right) \\
& \text { dan } \boldsymbol{d}^{\mathbf{0}}=\boldsymbol{H}_{\mathbf{0}} \boldsymbol{P}^{T}=\left(\begin{array}{l}
3 \\
2 \\
5
\end{array}\right) . \text { Dengan menggunakan Persamaan }(7) \\
& \text { diperoleh } \propto_{\mathbf{0}}=\mathbf{0 , 1 1}
\end{aligned}
$$

Iterasi 1.

Langkah 1 : Dengan menggunakan Persamaan (4) diperoleh, 
$X^{1}=\left(\begin{array}{l}0,5 \\ 0,5 \\ 0,5\end{array}\right)+0,1\left(\begin{array}{l}3 \\ 2 \\ 5\end{array}\right)=\left(\begin{array}{l}0,83 \\ 0,72 \\ 1,05\end{array}\right)$

Langkah 2 : Untuk $X^{1}$ memotong kendala kedua, $3 x_{1}+0 x_{2}+2 x_{3}=4,6$

Berdasarkan persamaan (2), tidak terdapat $\boldsymbol{U}$ sehingga

$\left.W(U)=b U^{T}=13,1 \neq F\left(X^{o}\right)=9,2\right)$ (belum optimal)

Langkah $3 \quad$ : Ambil k = 2 dengan menggunakan Persamaan (6), (5) dan (7) masingmasing diperoleh,

Iterasi 2.

$$
\boldsymbol{H}_{\mathbf{1}}=\left(\begin{array}{ccc}
0,31 & 0 & -4,6 \\
0 & 1 & 0 \\
-0,46 & 0 & 0,69
\end{array}\right), \boldsymbol{d}^{\mathbf{1}}=\boldsymbol{H}_{\mathbf{1}} \boldsymbol{P}^{\boldsymbol{T}}=\left(\begin{array}{c}
-1,38 \\
2 \\
2,07
\end{array}\right) \text { dan } \propto_{\mathbf{1}}=\mathbf{0}, \mathbf{0 7 3}
$$

Langkah 1 : Dengan menggunakan persamaan (4) diperoleh ,

$X^{2}=\left(\begin{array}{c}0,83 \\ 0,72 \\ 1,05\end{array}\right)+0,073\left(\begin{array}{c}-1,38 \\ 2 \\ 2,08\end{array}\right)=\left(\begin{array}{c}0,73 \\ 0,87 \\ 1,20\end{array}\right)$

Langkah 2 : Untuk $X^{2}$ memotong kendala 2 dan 3 sehingga, $3 x_{1}+0 x_{2}+2 x_{3}=4,6$ dan $1 x_{1}+4 x_{2}+0 x_{4}=4,2$.Selanjutnya berdasarkan Persaman (2) menunjukan $X^{2}$ bukan solusi optimal karena

$W(U)=b U^{T}=13,1 \neq F\left(X^{o}\right)$

Langkah 3 : Ambil k = 3 dengan menggunakan Persamaan (6), (5) dan (7) masingmasing diperoleh

$$
\boldsymbol{H}_{2}=\left(\begin{array}{ccc}
0,30 & -0,08 & -0,45 \\
-0,08 & 0,02 & 0,11 \\
-0,45 & 0,11 & 0,68
\end{array}\right), \boldsymbol{d}^{2}=\boldsymbol{H}_{2} \boldsymbol{P}^{T}=\left(\begin{array}{c}
-1,51 \\
0,38 \\
2,26
\end{array}\right) \text { dan } \propto_{2}=\mathbf{0 , 4 2}
$$

Iterasi 3.

Langkah 1 : Dengan menggunakan Persamaan (4) diperoleh,

$\boldsymbol{X}^{3}=\left(\begin{array}{c}0,73 \\ 0,87 \\ 1,20\end{array}\right)+0,42\left(\begin{array}{c}-1,51 \\ 0,38 \\ 2,26\end{array}\right)=\left(\begin{array}{c}0,1 \\ 1,025 \\ 2,15\end{array}\right)$

Langkah 2 : Untuk solusi $\boldsymbol{X}^{3}$, memotong kendala1,2 dan 3 sehingga diperoleh $x_{1}+2 x_{2}+x_{3}=4,3 ; 3 x_{1}+0 x_{2}+2 x_{3}=4,6$ dan $x_{1}+4 x_{2}+0 x_{3}=4,2$

Berdasarkan Persamaan (2) solusi $\boldsymbol{X}^{3}$ adalah solusi optimal karena dipenuhi $W(U)=b U^{T}=13,1=F\left(X^{o}\right)$ 


\section{Kesimpulan}

Metoda modifikasi proyeksi gradien memberikan sebuah alternatif pada penyelesaian pemrograman linear. Hal yang menarik pada metoda modifikasi gradien adalah titik fisibel awal tidak harus sebagai titik ekstrim seperti halnya pada metoda Simpleks. Selain itu diperoleh sebuah kenyataan bahwa ternyata metoda proyeksi gradien tidak hanya dapat digunakan pada pemrograman nonlinear, tetapi dapat juga dimanfaatkan untuk menyelesaikan pemrograman linear. Meskipun demikian harus diakui juga bahwa pemakaian metoda proyeksi gradien pada pemrogramn linear relatif lebih rumit dibandingkan dengan metoda Simpleks. Metoda modifikasi proyeksi gradien pada pemrograman linear yang telah diteliti terbatas hanya pada masalah maksimum. Selanjutnya peneliti menyarankan untuk meneliti pemakaian metoda modifikasi proyeksi gradien pemrograman linear untuk masalah minimum.

\section{Daftar Pustaka}

[1] H. A. Taha, OperationsResearch: An Introduction, th ${ }^{d}$ Edition,Macmillan Publishing, New York, 1982.

[2] M. S. Bazaraa and C. M. Shetty, Nonlinear Programming:Theory and Algorithms, $2^{\text {th }}$ Edition, John Wiley \& Sons, 1993.

[3] W. L. Wiston, Operations Research, Applications and Algorithms, $4^{\text {th }}$ Edition, Brooks/Cole-Thomson Learning, Belmount, 2004.

[4] S. Tantawy, A New Procedure for Solving Linier Programming Problem with Sensitivity Analysis, Trends in Applied Sciences Researc, 14: 7-11, 2019.

[5] S. S. RAO, OPTIMIZATION Theory and Applications, second Edition, WILEY EASTERN LIMITED, 1984.

[6] F. S. Hillier dan G. J. Liebermen, Introduction Operations Research, Seventh Edition, McGraw-Hill, New York, 2001.

[7] S. Lang, Linear Algebra, Second edition, Addison-Wesley Publishing Company, New York, 1970.

[8] P.R. Murthy, Operation Research, Second Eddition, New Age Publisher, New Delhi, 2007.

[9] C. S. Bightler, D. T. Phillips, D. J. Wilde, Foudations of Optimization, second edition, Prentice Hall of India Limited, 1982.

[10] E. D. Nering, Linear Algebra and MatrixTheory, Second Edition, John Wiley \& Sons, Inc, New York.

[11] W. Rudin, Principle Mathematical Analysis, Third Edition, McGraw-Hill book Company Singapore, 1976.

[12] Purcell, Calculus, Ninth Edition, Prentice Hall, 1978. 